\title{
1 A field investigation of the thermal environment and adaptive thermal behavior in bedrooms in different climate regions in China
}

\author{
Jinyu Liu ${ }^{1}$, Junjie Liu ${ }^{1}$, Dayi Lai ${ }^{1,2}$, Jingjing Pei $^{1,{ }^{*}}$, Shen $\mathrm{Wei}^{3,{ }^{*}}$ \\ ${ }^{1}$ Tianjin Key Laboratory of Indoor Air Environmental Quality Control, School of \\ Environmental Science and Engineering, Tianjin University, Tianjin 300072, China \\ ${ }^{2}$ School of Design, Shanghai Jiao Tong University, Shanghai 200240, China \\ ${ }^{3}$ The Bartlett School of Construction and Project Management, University College London \\ (UCL), London, WC1E 7HB, UK \\ *Phone: +86-022-27409500, Email: jpei@tju.edu.cn \\ *Phone: +44-07545479329, Email: shen.wei@ucl.ac.uk
}

\section{Acknowledgement}

This research was partially supported by the National Key Project of the Ministry of Science and Technology, China, on "Green Buildings and Building Industrialization" through Grant No. 2016YFC0700500. The authors would like to express our gratitude to Prof. Kailiang Huang from Shenyang Jianzhu University; Prof. Yiwen Jian from Beijing University of Technology; Prof. Yuexia Sun, Prof. Hejiang Sun, and Prof. Xiong Shen from Tianjin University; Prof. Haiguo Yin from Xi'an University of Architecture and Technology; Prof. Hongwei Tan from Tongji University; Dr. Yao Gao from Shenzhen Institute of Building Research Co., Ltd.; and all the graduate students for their help in discussing the results and collecting the study data . 
Sleep thermal environments substantially impact sleep quality. To study the sleep thermal environment and thermal comfort in China, this study carried out on-site monitoring of thermal environmental parameters in peoples' homes, including 166 households in five climate zones, for one year. A questionnaire survey on sleep thermal comfort and adaptive behavior was also conducted. The results showed that the indoor temperature for sleep in northern China was more than $4^{\circ} \mathrm{C}$ higher than that in southern China in winter, while the indoor temperatures for sleep were similar in summer. Furthermore, $70 \%$ of people were satisfied with their sleep thermal environment. Due to the use of air conditioning and window opening in various areas in summer, people were satisfied with their sleep thermal environments. Due to the lack of central heating in the southern region in winter, people feel cold, and their sleep thermal environment needs further improvement. The insulated bedding in northern China was 1.83 clo and 2.67clo in summer and winter, respectively, with 2.21 clo and 3.17 clo, respectively, for southern China. Both northern and southern China used air conditioning only in summer. People in southern China opened their windows all year, while those in northern China opened their windows during the summer and transitional periods.

KEYWORDS: Sleep thermal environment; Thermal comfort; Long-term field measurement; Questionnaire survey; Human behavior; Residential buildings

\section{Practical Implications:} in China. 
2. South and North China have different thermal environments and behaviors in the winter.

3. Bedding insulation was highly correlated with temperature and season.

4. Windows provide a popular adaptive behavior opportunity in residential buildings in China.

5. The indoor temperature was $28^{\circ} \mathrm{C}-30^{\circ} \mathrm{C}$ and $14{ }^{\circ} \mathrm{C}-22^{\circ} \mathrm{C}$ in summer and winter in China, respectively.

\section{Introduction}

Sleep accounts for one-third of people's lives and is used to help overcome fatigue, recover energy to protect from brain damage ${ }^{1}$, and maintain physical and mental health ${ }^{2}$. Sleep disorders, however, are not uncommon among the general public, and approximately one-third of adults suffer from relevant issues ${ }^{3}$. Poor sleep quality can damage the physical and mental health of people, especially adolescents ${ }^{4}$ and the elderly ${ }^{5,6}$. For sleep quality, there are many influencing factors, such as acoustic environment, visual environment, thermal environment and human psychological stress, with thermal environment been suggested as a major factor 7. A comfortable indoor thermal environment is even more important for sleeping than for awake times due to a reduced metabolic rate, which regulates the core temperature of the human body, and limited adaptive abilities ${ }^{8}$. A well-maintained indoor thermal environment during the sleeping period contributes to a reduced number of wake-ups caused by thermal discomfort, hence improving sleep quality ${ }^{9,10}$. To improve people's health, it is extremely important to understand the thermal environment during their sleeping period and their thermal requirements 
and develop proper guidance to support the design and operation of buildings.

Currently, official definitions of the thermal requirements during the sleeping period have been adopted in only some major building design standards, and the definitions are much simpler than those for the periods spent awake. The World Health Organization (WHO) has recommended a minimum bedroom temperature of $17^{\circ} \mathrm{C}{ }^{11}$, and the Chartered Institution of Building Services Engineers (CIBSE) has suggested in its Guide A that for dwellings, 'thermal discomfort and quality of sleep begin to decrease if the bedroom temperature rises much above $24^{\circ} \mathrm{C}$ ' and 'it is desirable that bedroom temperatures at night should not exceed $26^{\circ} \mathrm{C}$ unless there is some means to create air movement in the space, e.g., ceiling fans'. Additionally, the design temperature has been suggested to be $17-19^{\circ} \mathrm{C}$ for winter and $23-25^{\circ} \mathrm{C}$ for summer ${ }^{12}$. Other major building design standards, such as ISO7730 ${ }^{13}$, ASHRAE $55{ }^{14}$, EN15251 ${ }^{15}$ and GBT50736 ${ }^{16}$, have not given any quantitative recommendations about the appropriate thermal environment for sleeping period. Currently, there is no recommended bedroom temperature for sleeping in China. Therefore, it is needed to collect field data in terms of the actual thermal conditions for sleeping in China, especially at different geographical areas.

To better understand people's thermal requirements during sleeping period, researchers have conducted relevant studies. According to the data collection methods, these studies can be classified into two types, i.e., experimental studies and field studies, as described separately below.

Experimental studies were carried out in climate chambers, where major environmental parameters, such as temperature and humidity, and nonenvironmental parameters, such as 
bedding insulation, were strictly controlled ${ }^{17}$. Using this method, researchers can adjust each controllable parameter separately to justify its impact on people's sleep quality and thermal comfort. The results from these studies have shown that the neutral temperature for sleeping with shorts on only was between $28^{\circ} \mathrm{C}$ and $32^{\circ} \mathrm{C}^{18-20}$. When adding duvets with different insulation levels, the neutral temperature could be reduced to approximately $21 \cdot 2-30.9^{\circ} \mathrm{C}^{21-24}$. In two studies carried out by Lan et al. ${ }^{25,26}$, the most comfortable temperatures in winter and summer were suggested to be $23^{\circ} \mathrm{C}$ and $26^{\circ} \mathrm{C}$, respectively. Lin et al. ${ }^{27}$ studied the effects of different bedding solutions and updated Fanger's PMV-PPD model by correcting the definitions of relevant parameters for sleeping conditions. Based on the basic principle of the heat balance of human bodies, Lan et al. ${ }^{28}$ developed a model to predict the thermal neutrality of sleeping people by dividing the human body into two parts, i.e., the part in contact with the bed and the part not in contact with the bed. Experimental data have been used to validate the accuracy of this prediction model.

Field studies in this research area tried to collect data from actual buildings for analysis. When using this method, onsite environmental monitoring instruments were required to measure environmental parameters, and questionnaire surveys were used to collect relevant subjective information, such as people's clothing and bedding insulation, as well as their sleeping thermal comfort and quality. Lin et al. ${ }^{29}$ performed a survey in Hong Kong in summer and obtained 544 valid questionnaires. From the survey, they found that the local residents liked to set their airconditioning system at a low temperature when sleeping and used bedding with high thermal insulation to maintain thermal comfort. In this study, however, no environmental parameters were measured. Kim et al. ${ }^{30}$ conducted a survey with 24 female subjects in Korea over one 
year, and they found that the subjects' best sleep quality occurred in spring and the worst

111 occurred in summer. From this study, the comfortable temperature for the whole year was 112 suggested to be between $24^{\circ} \mathrm{C}$ and $26^{\circ} \mathrm{C}$, with a recommended maximum temperature of $28.1^{\circ} \mathrm{C}$.

113 Additionally, the ranges of comfortable temperature for different seasons were recommended 114 as well. In Japan, a field study with 31 participants found that the actual neutral temperature for sleeping was lower than the recommended temperature setting for cooling in summer, which was $28^{\circ} \mathrm{C}$, as the participants showed good thermal satisfaction and sleep quality when the bedroom air temperature was ranging between $26.3^{\circ} \mathrm{C}$ and $27.9^{\circ} \mathrm{C} 31$. Liu et al. ${ }^{32}$ conducted a field study investigating people's sleep thermal comfort in some rural areas in northwestern China in the winter with 772 valid collected questionnaires the corresponding environmental parameters monitored. From the study, they found that the sleeping comfort temperature was ranging from $7.83^{\circ} \mathrm{C}$ to $16.38^{\circ} \mathrm{C}$, which was much lower than the recommended values from standards. As similar result was found by Wang et al. ${ }^{33}$, who investigated the thermal requirements of 58 people living in the rural areas of severely cold regions in China, with a neutral temperature of $13.1^{\circ} \mathrm{C}$ in winter identified. A possible reason for this low temperature requirement for sleeping is the use of heated Kangs and thick quilts in these areas, making a much less tolerable indoor temperature condition.

According to the above literature review, both experimental study and field study methods have been adopted to evaluate people's thermal requirements and quality during sleeping period. The former method enables researchers to control the experimental conditions more accurately and freely, while the latter method can better reflect the actual condition in real buildings, which is

131 similar to the debate between Fanger's PMV-PPD model and the adaptive thermal comfort 
model ${ }^{34}$. Although some data have been collected from China, all of them were from rural areas, and data from cities are still not available. Additionally, all existing studies collected data from single geographical areas; the impact of different climate zones/conditions cannot be investigated, and this is extremely important for countries with huge territories, such as China.

To fill the above gap, this paper introduces the major results from a year-long field study conducted in nine cities in China in five different climatic zones. In the study, major environmental parameters, including air temperature and relative humidity, were monitored with electronic devices, and questionnaires were used to collect data about people's thermal comfort, sleep quality, total bedding insulation, window states and usage of air condition systems, focusing on people's sleeping period. This study provides quantitative evidence about the current sleeping conditions of people in different climate zones in China, together with their sleep quality and thermal requirements, to guide future building design and operation.

\section{Methodology}

\subsection{Case study buildings}

To obtain field data in terms of the thermal environment during sleeping period with a consideration of geographical impact, a year-long study was carried out in five climatic regions in China, i.e., the Severely cold (SC) zone, Cold (C) zone, Hot summer and Cold winter (HSCW) zone, Mild (M) zone and Hot Summer and Warm Winter (HSWW) zone, as shown in Figure 1. The five climatic zones were defined by the code for the thermal design of civil buildings in China, i.e., GB50176-2016 ${ }^{35}$, and the selected cities in this study were Urumqi (SC), Shenyang (SC), Beijing (C), Tianjin (C), Xi'an (C), Shanghai (HSCW), Chongqing (HSCW), Kunming 
(M) and Shenzhen (HSWW). The survey was carried out in the bedrooms of traditional apartments in China, with floor levels ranging between floor 1 to floor 30. Every apartment we investigated in SC and $\mathrm{C}$ had central heating, and while there is no central heating in other areas, split-cooling air conditioners can be reversed to provide heating when required.

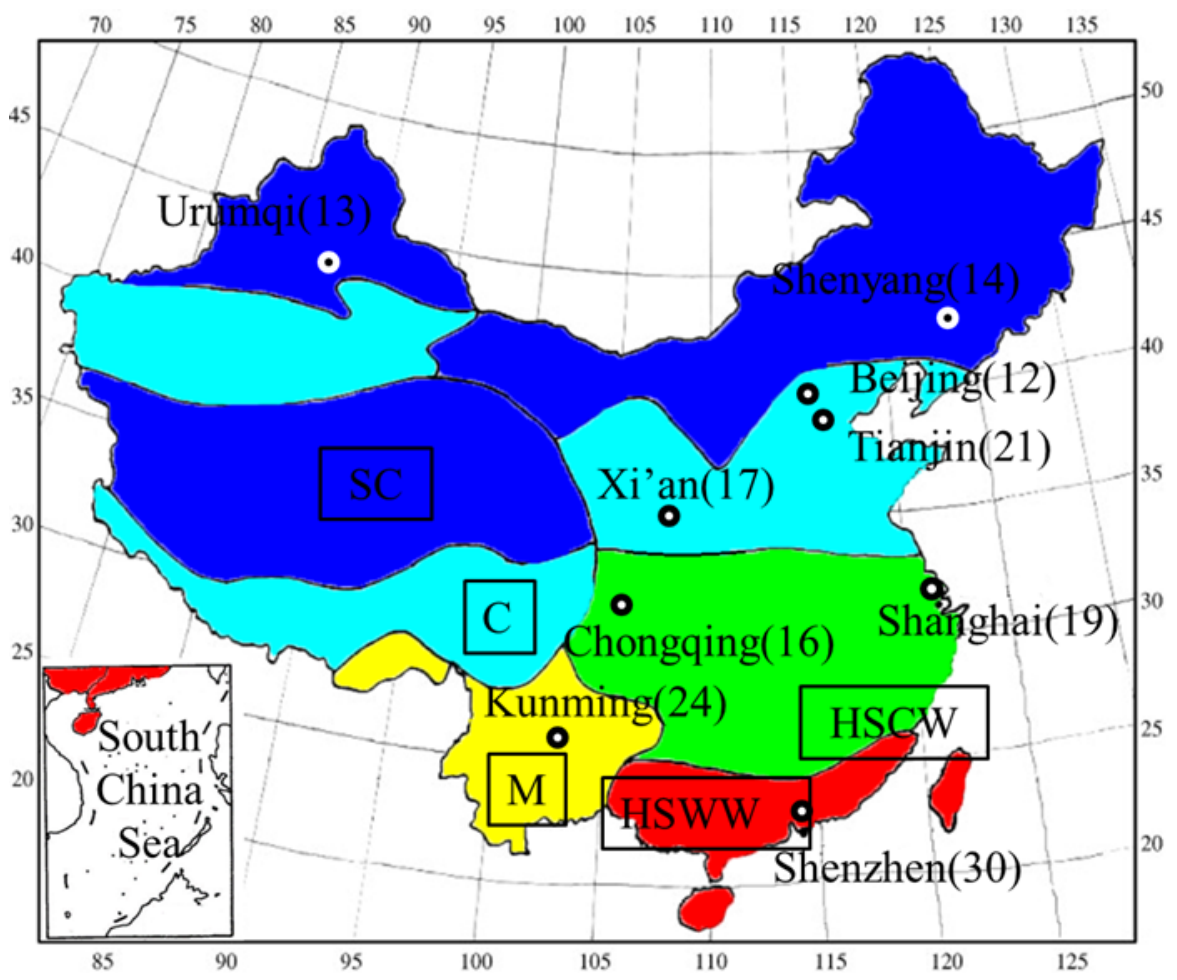

Figure 1 The locations of the case study buildings and their climate zones ${ }^{[1]}$

In the study, all monitored subjects had been living in the investigated apartments for over a year, and therefore can be considered to be adapted to the local climate. The survey included a total of 166 bedrooms and participants, with 69 males and 97 females, and an average age of 37.5 years. Table 1 has listed some basic information about the participants of this study.

\footnotetext{
${ }^{1}$ The number following the city name represents the number of monitored residences in that city
} 
Table 1 Basic information about the participants

\begin{tabular}{cccc}
\hline City & Number of Subjects (Male/Female) & Age & Percent of subjects \\
\hline Urumqi & $13(5 / 8)$ & $43.9 \pm 9.2$ & $7.8 \%$ \\
Shenyang & $14(7 / 7)$ & $34.2 \pm 10.5$ & $8.4 \%$ \\
Beijing & $12(6 / 6)$ & $38.5 \pm 10.3$ & $7.2 \%$ \\
Tianjin & $21(9 / 12)$ & $36.9 \pm 12.3$ & $12.7 \%$ \\
Xi'an & $17(5 / 11)$ & $33.3 \pm 5.7$ & $10.2 \%$ \\
Shanghai & $19(7 / 12)$ & $38.5 \pm 8.8$ & $11.5 \%$ \\
Chongqing & $16(6 / 10)$ & $40.1 \pm 9.1$ & $9.6 \%$ \\
Kunming & $24(10 / 14)$ & $39.3 \pm 9.5$ & $14.5 \%$ \\
Shenzhen & $30(13 / 17)$ & $33.1 \pm 8.8$ & $18.1 \%$ \\
ALL & $166(69 / 97)$ & $37.5 \pm 9.3$ & $100 \%$ \\
\hline
\end{tabular}
different geographical locations of the monitored buildings and their local climate conditions,

169 the exact dates of these three periods could be different between cities, as summarized in Table 2. 
Table 2 Season definitions in this study

\begin{tabular}{|c|c|c|c|}
\hline City & Summer & Winter & Transitional \\
\hline Urumqi & 09 June-23 August & 07 October-16 April & $\begin{array}{l}\text { 17April-08 June } \\
24 \text { August }-06 \\
\text { October }\end{array}$ \\
\hline Shenyang & 04 June-26 August & 10 October-17 April & $\begin{array}{c}\text { 18April-03 June } \\
27 \text { August -09 } \\
\text { October }\end{array}$ \\
\hline Beijing & 24 May-09 September & 03 November-24 March & $\begin{array}{c}25 \text { March-23 May } \\
\text { 10September -02 } \\
\text { November }\end{array}$ \\
\hline Tianjin & 24 May-19 September & 08 November-23 March & $\begin{array}{c}24 \text { March-23 May } \\
20 \text { September -07 } \\
\text { November }\end{array}$ \\
\hline Xi'an & 15 May-15 September & 07 November-12 March & $\begin{array}{l}13 \text { March-14 May } \\
\text { 16September -06 } \\
\text { November }\end{array}$ \\
\hline Shanghai & 15 May-05October & 08 December -02 March & $\begin{array}{c}03 \text { March-14 May } \\
\text { 06October -07 } \\
\text { December }\end{array}$ \\
\hline Chongqing & 01 May-17September & 11 December -24 February & $\begin{array}{c}23 \text { February-30 April } \\
\text { 18September -10 } \\
\text { December }\end{array}$ \\
\hline Kunming & / & 15 December -12 February & $\begin{array}{c}\text { 13February-14 } \\
\text { December }\end{array}$ \\
\hline Shenzhen & 30 March-23November & l & $\begin{array}{c}\text { 24November-29 } \\
\text { March }\end{array}$ \\
\hline
\end{tabular}

\subsubsection{Objective measurements}

During the survey, both temperature and relative humidity were measured onsite using Ikair instruments, with a measurement accuracy of $\pm 0.3^{\circ} \mathrm{C}$ for temperature and $\pm 3 \%$ for relative humidity. During the measurement period, the sensors were placed on a bedside table in the main bedroom, as shown in Figure 2, to monitor and record participants' surrounding thermal environments every minute. The outdoor temperature was concurrently measured and recorded 

apartments.

Figure 2 Monitoring device for temperature and relative humidity

\subsubsection{Subjective measurements}

In addition to the objective measurements introduced above, subjective measurements were carried out using questionnaires to collect data about people's thermal sensations.

To prevent survey fatigue from participants, the questionnaire was issued every ten days. This arrangement can also provide good coverage of thermal conditions, especially for outdoor environment. The questionnaire has nine questions, as listed in Table 3, and they were sent to the participants' smartphones at $9 \mathrm{am}$, with a notice sent to them the night before the survey. The participants were asked to fill out the questionnaire according to their sleeping experience the previous night. During the survey, all participants were aware of that the survey was only

201 for their bedrooms, not including other rooms in their apartments. 
using the ASHRAE's seven scale method ${ }^{14}$. The overall insulation level of their bedding systems was obtained using the calculation method adopted by Lin ${ }^{36}$ for estimating bedding thermal resistance in Asia, with the clo values converted from participants' answers to Question 5 in Table 3. The values for clothing insulation were as followings: vest/shorts $(0.1$ clo), vest + shorts $(0.18 \mathrm{clo})$, short-sleeved T-shirt + shorts/short night skirt $(0.34 \mathrm{clo})$, short-sleeved T-shirt + trousers/nightdress $(0.42 \mathrm{clo})$, long sleeve T-shirt + shorts $(0.48 \mathrm{clo})$, long sleeve T-shirt + trousers $(0.57 \mathrm{clo})$, and thick thermal pajamas + thermal pants $(0.96 \mathrm{clo})$; and those for bedding insulation were as follows: no cover (0.9clo), blanket (1.65clo), thin duvet (1.98clo), thick duvet (2.7clo), and more than one thick duvet (3.38clo). The overall thermal insulation was the sum of both bedding insulation and clothing insulation. According to ASHREA $55^{14}$, participants' metabolic rate when sleeping was selected as 0.7 met. for summer, 767 for winter and 1728 for transitional season. 
Table 3 Questions and options used in the thermal comfort questionnaire

\begin{tabular}{|c|c|}
\hline Questions & Options \\
\hline $\begin{array}{l}\text { 1) How do you feel about the thermal } \\
\text { environment when you were sleeping last night }\end{array}$ & $\begin{array}{l}\text { Cold, Cool, Slightly cool, Neutral, Slightly } \\
\text { warm, Warm, Hot }\end{array}$ \\
\hline $\begin{array}{l}\text { 2) How do you think your sleeping } \\
\text { environment last night could change }\end{array}$ & Cooler, No change, Warmer. \\
\hline & Vest/shorts, Vest + shorts, Short-sleeved T-shirt \\
\hline $\begin{array}{l}\text { 3) Please select the most appropriate } \\
\text { combination of garments to describe you worn } \\
\text { for sleeping last night }\end{array}$ & $\begin{array}{l}\text { + shorts/short night skirt, Short-sleeved T-shirt } \\
+ \text { trousers/nightdress, Long sleeve T-shirt }+ \\
\text { shorts, Long sleeve T-shirt }+ \text { trousers, Thick } \\
\text { Thermal Pajamas + Thermal Pants. }\end{array}$ \\
\hline $\begin{array}{l}\text { 4) How do you feel about the humidity level } \\
\text { when you were sleeping last night }\end{array}$ & Wet, Neutral, Dry. \\
\hline $\begin{array}{l}\text { 5) Please select the most appropriate quilt to } \\
\text { describe what you worn for sleeping last night }\end{array}$ & $\begin{array}{l}\text { No cover, blanket, thin duvet, thick duvet. } \\
\text { More than one thick duvet. }\end{array}$ \\
\hline $\begin{array}{l}\text { 6) Please select the most appropriate mattress } \\
\text { to describe what you used last night }\end{array}$ & Cotton sheets, straw mats, bamboo mats \\
\hline $\begin{array}{l}\text { 7) Did you sleep with your air conditioner on } \\
\text { last night }\end{array}$ & Yes, No \\
\hline $\begin{array}{l}\text { 8) If } \mathrm{ON} \text {, please write down the setting } \\
\text { temperature of your air conditioner in }{ }^{\circ} \mathrm{C}\end{array}$ & Text \\
\hline $\begin{array}{l}\text { 9) Did you leave your window open last night } \\
\text { when you were sleeping }\end{array}$ & Yes, No \\
\hline
\end{tabular}




\section{Results}

The following are the results from both the environmental monitoring and questionnaire surveys.

\subsection{Thermal environmental parameters}

\subsubsection{Outdoor environmental parameters}

Figure 3 depicts the data collected from different regions during the experimental period for two main outdoor environmental parameters, i.e., nighttime outdoor temperature (Figure 3a) and nighttime outdoor relative humidity (Figure 3b), based on their monthly average values.

Figure 3a shows that all investigated regions generally had lower temperatures outdoors in winter and higher temperatures outdoors in summer. However, the range of temperature variation was different, with the SC region having the largest difference (maximum temperature difference $=34.8^{\circ} \mathrm{C}$ ) and the HSWW region having the smallest difference (maximum temperature difference $=11.6^{\circ} \mathrm{C}$ ). Additionally, northern regions, such as the $\mathrm{C}$ and the $\mathrm{SC}$ regions, appeared to be much colder in winter than southern regions, including the $\mathrm{M}$, the HSCW and the HSWW regions, with the largest difference occurring between the SC region and the HSWW region, which was almost $30^{\circ} \mathrm{C}$. In summer (June to August), however, the difference between regions appeared to be much less. This was similar to the results from daytime thermal environmental studies ${ }^{37}$.

247 From Figure 3b, a lower level of relative humidity can be observed in the SC (annual average $248=63 \%$ ) and the $\mathrm{C}$ regions (annual average $=62 \%$ ) comparing to that in the HSCW (annual 
average $=79 \%)$, the $\mathrm{M}($ annual average $=79 \%)$ and the HSWW (annual average $=80 \%)$ regions

250 during the whole year. It reflects that northern China is drier than southern China throughout

251 the year, especially in winter. Additionally, both the HSWW and the HSCW regions had high

252 levels of relative humidity $(>70 \%)$ throughout the whole year.

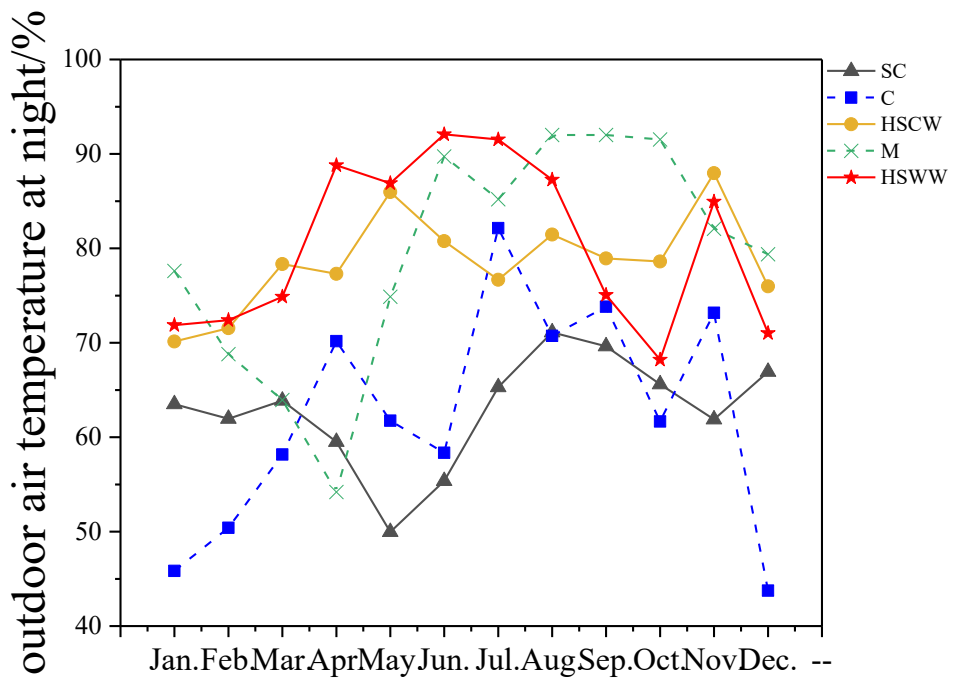

(a) Outdoor temperature

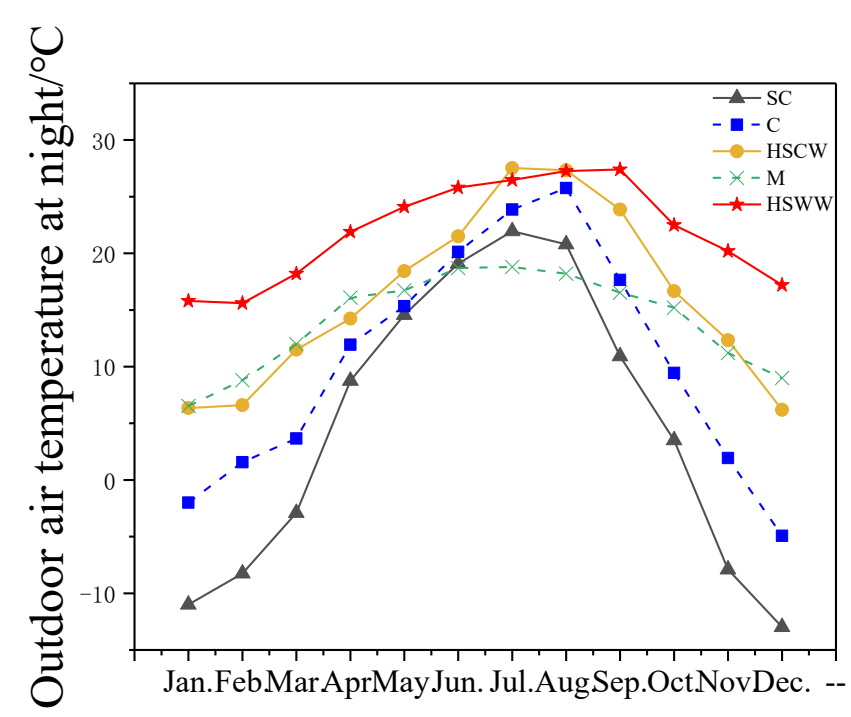

(b) Outdoor relative humidity

Figure 3 Monitored monthly average nighttime outdoor temperature and outdoor relative 


\subsubsection{Indoor environmental parameters}

260

261

262

263

264

265

266

267

268

269

270

271

272

273

274

275

276

277

Figure 4 depicts the collected nighttime indoor temperature (Figure 4a) and nighttime indoor relative humidity (Figure $4 b$ ) at different regions, based on their monthly average values.

Figure $4 \mathrm{a}$ clearly shows that the monitored buildings in the HSCW, the M and the HSWW regions had much lower indoor temperatures in December, January and February than those in the $\mathrm{C}$ and the $\mathrm{SC}$ regions, with averages of $14.7^{\circ} \mathrm{C}(\mathrm{HSCW}), 18.4^{\circ} \mathrm{C}(\mathrm{M}), 17.8^{\circ} \mathrm{C}$ (HSWW), $22.3^{\circ} \mathrm{C}(\mathrm{C})$ and $23.1^{\circ} \mathrm{C}$ (SC). Compared with CIBSE Guide A (which guides bedroom temperature) for winter (as shown in the dotted line in the figure), the average sleep temperature in the HSCW regions was significantly below the recommended minimum limit of $17^{\circ} \mathrm{C}$, while those of the $\mathrm{C}$ and the HSWW regions were below the recommended value of $19^{\circ} \mathrm{C}$. This is mainly due to the existence of central heating systems in northern China to maintain indoor temperature, and this is not provided for most buildings in southern China. Due to the existence of mechanical and natural cooling in both southern and northern China to regulate indoor temperature during the summer and transitional periods, Figure 4a shows that the indoor temperature difference between the regions was not significant for the remainder of the year. However, the mean air temperature during sleep in the summer was ranging from $28^{\circ} \mathrm{C}$ to $30^{\circ} \mathrm{C}$ in all regions, much higher than the recommended comfort temperature in CIBSE Guide A $\left(23^{\circ} \mathrm{C}-25^{\circ} \mathrm{C}\right)$. In combination with the use of air conditioning in Section 3.3.2, it was found that although most people used air conditioning in summer, their room temperature was generally remained above $28^{\circ} \mathrm{C}$. with $\mathrm{AC}$ setpoint between $26^{\circ} \mathrm{C} \sim 27^{\circ} \mathrm{C}$ (see Section 3.3.2). The possible reason is their concern about energy conservation and economic, so they are more likely to choose a higher AC setpoint to save as much energy as possible. 
From Figure $4 \mathrm{~b}$, the level of relative humidity indoors seemed to be much lower in buildings in northern China (i.e., the SC and the $\mathrm{C}$ regions) than those in southern China (i.e., the HSCW,

283 the $\mathrm{M}$ and the HSWW regions), and this phenomenon is consistent with what happened outdoors; for residential buildings, moisture mainly comes from outdoors by either ventilation or infiltration ${ }^{38}$. Additionally, the higher indoor temperature in winter due to the use of heating systems may also be a reason for the lower relative humidity. For both regions in northern China, the levels of relative humidity in summer increased due to changes in the outdoor humidity level. However, as outdoor temperature at night is lower than indoor temperature (Figure 3a and 4a), outdoor relative humidity was found to be higher than indoor relative humidity. In southern China, the outdoor relative humidity is high, and moisture enters the room from the outside. At the same time, people apply dehumidification measures such as using air conditioning, and therefore indoor relative humidity was found to be lower than outdoor relative humidity.

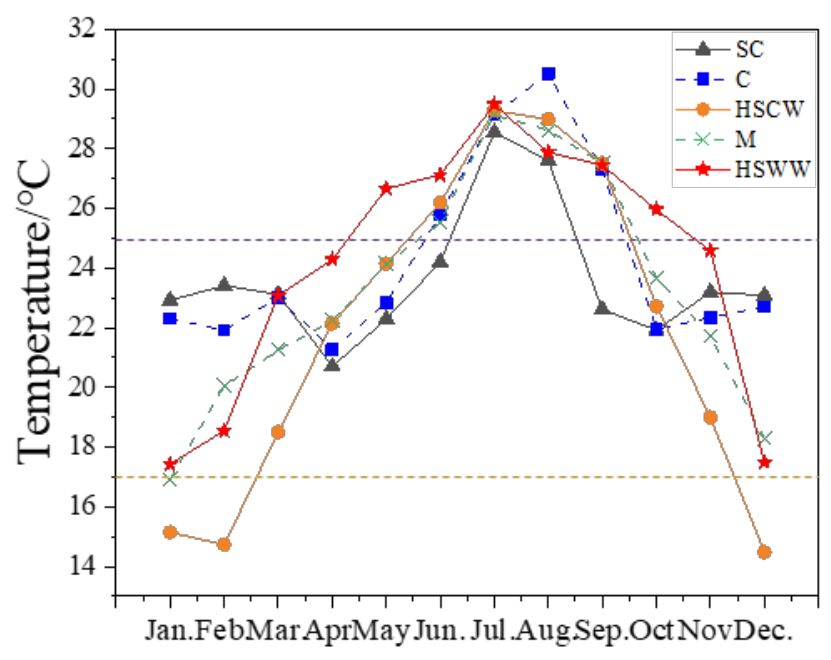

(a) Indoor temperature 


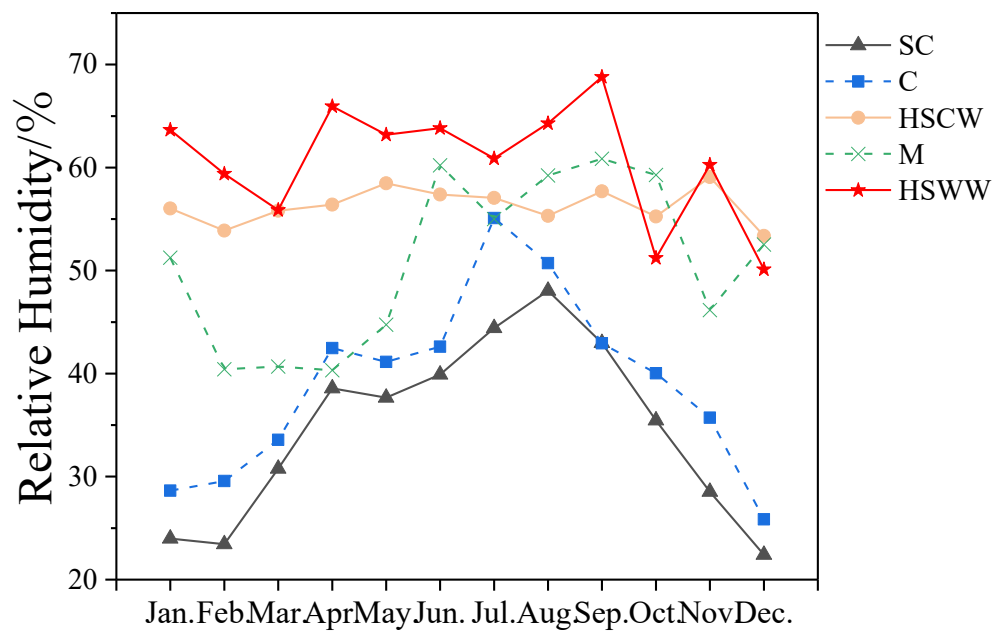

(b) Indoor relative humidity

\subsection{Thermal sensation}

\subsubsection{Thermal sensation}

Figure 5 depicts the major results from occupants' subjective evaluations of their thermal sensations when sleeping; the questionnaires were given to them in the following morning. The data were analyzed from two aspects, namely, sensation distribution (Figure 5a) and seasonal variation (Figure 5b).

From the results shown in Figure 5a, most participants in this study indicated acceptable thermal sensations during sleeping, as over $70 \%$ of votes were between -1 (slightly cool) and +1 (slightly warm). For neutral condition (TSV=0), it appeared that people living in southern China (i.e., the HSCW, the M and the HSWW regions) voted more frequently for this category. For 
311 the other conditions, however, the variations between climatic zones seemed to be not 312 significant.

313 Figure $5 \mathrm{~b}$ further analyzes the data in terms of the impact of season, i.e., winter, summer and

314 transitional, as people experienced different outdoor climatic conditions and performed 315 different behaviors between seasons. Apparently, during transitional season, people from 316 different regions reported similar average thermal sensations. For summer and winter seasons, 317 however, it seemed that people living in northern China felt warmer in both winter and summer, 318 than those living in southern China. During wintertime, this difference was probably due to the 319 existence of central heating in northern China, which resulted in higher indoor temperatures, as 320 shown in Figure 4a. For summer time, Figure 4a shows similar indoor temperature conditions 321 and this phenomenon could be due to occupant climate adaptations ${ }^{39-41}$. Generally, southern 322 China is warmer than northern China, as shown in Figure 1a; therefore people living there have 323 a higher tolerance for warm environment ${ }^{42}$. Combining the two figures, it should be noted that $70 \%$ of people were satisfied, with thermal sensations between -1 and 1 . However, satisfaction 325 may not mean healthy. The evidence provided in this study will help to identify whether this 326 adapted sleeping environment by Chinese people in different geographical regions is healthy. 327 Additionally, the remaining 30\% who indicated dissatisfaction also needs further investigations to explore possible reasons and solutions. 


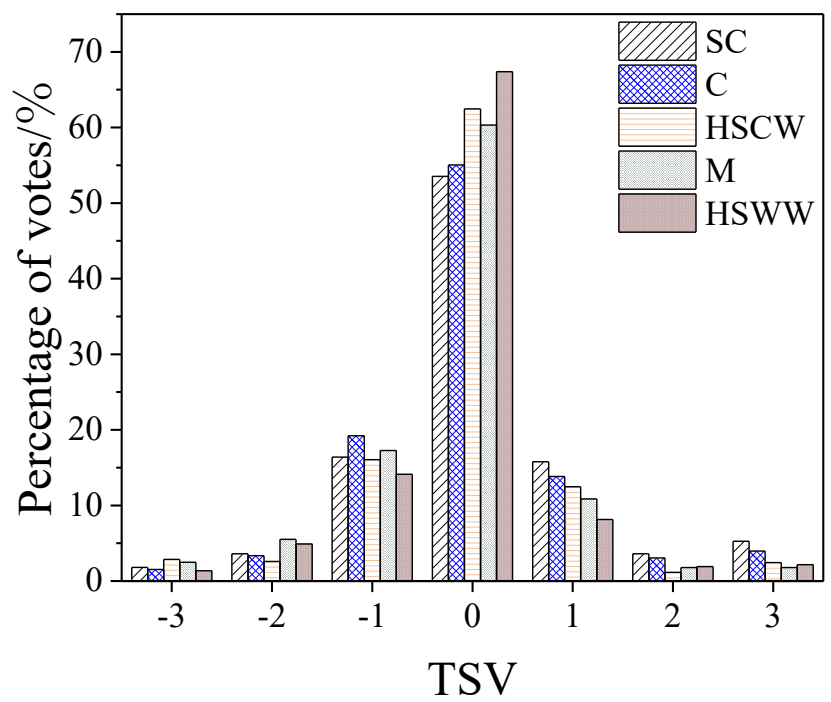

(a) Sensation distribution

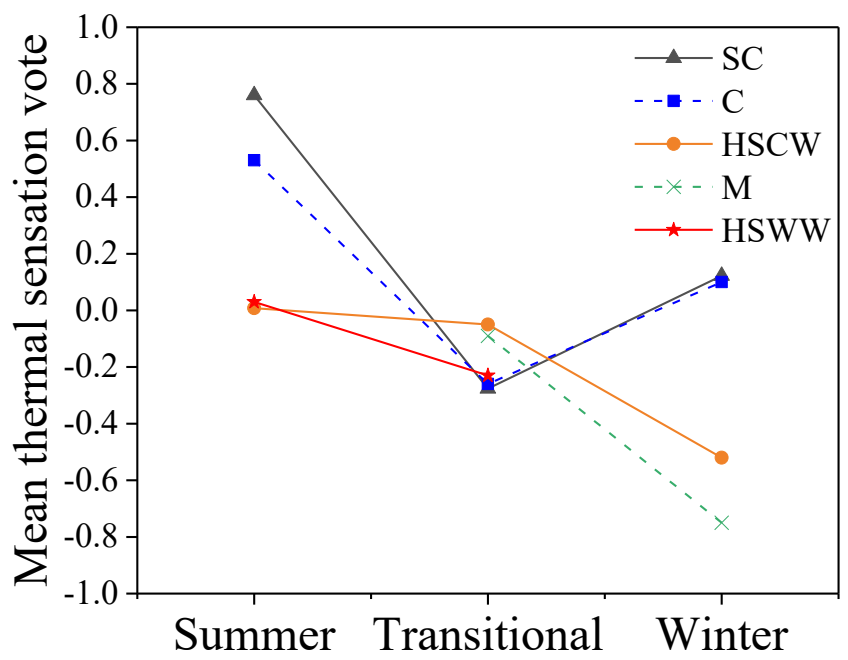

(b) Seasonal variation ${ }^{[2]}$

Figure 5 Occupant thermal sensation when sleeping during the survey period

As defined by Humphreys and $\mathrm{Nicol}^{43}$, the adaptive approach refers to the notion that if a

\footnotetext{
${ }^{2}$ According to the season classification method used in Section 2.1, the HSWW region has no winter season and the $\mathrm{M}$ region has no summer season. This is common in China due to its large territory.
} 
change occurs such as to produce discomfort, people react in ways that tend to restore their comfort'. Therefore, anything people are doing to restore their thermal comfort, including adjusting air conditioning setpoint and regulating heating setpoint would be classified as adaptive behaviors. However, not all systems in China provide adaptive opportunities to building occupants. For example, central heating systems popularly adopted in northern China, TRVs (Thermostatic Radiator Valves) are rarely installed and therefore output of these systems cannot be adjusted by residents based on their thermal requirements. In this study, people's adaptive behaviors on bedding insulation, AC operation and window opening will be analyzed.

\subsubsection{Bedding insulation}

Changing clothing insulation is a major adaptive behavior that can people use to maintain thermal comfort when awake ${ }^{44}$, especially to adapt to changing outdoor climate ${ }^{45}$. When sleeping, people often change the insulation level of their bedding systems to fulfill their thermal requirements ${ }^{36}$. Figure 6 depicts and compares the collected bedding insulation levels in different climate regions in summer, transitional and winter seasons. It clearly reflects that in all regions, people would change their bedding insulation between seasons, with the lowest insulation level found in summer and the highest insulation level found in winter. Additionally, people living in northern regions used less insulated bedding in both summer and winter than those living in southern regions. For summer time, this may because of their low tolerance to the environment, and for wintertime, it may because of the existence of central heating systems providing warmer indoor environment. Therefore, the adaptation in northern China seems to be different from that in southern China, as shown in Figure 4a. This finding agrees with results 
357 from one existing study ${ }^{46}$. For transitional season, however, the difference between regions was not significant.

Figure 6 Total insulation of the bedding system when people are sleeping

Many scholars have investigated the relationship between bedding insulation and indoor

temperature $^{47} 48$. Table 4 has summarized some major statistical parameters, at a confidential level of $95 \%$. Statistically, for all regions the indoor temperature had a significant influence $(p<0.05)$ on the overall bedding insulation. People can adapt to their changing indoor thermal environment by either increasing or decreasing the amount of bedding insulation. From this study, high correlations between overall bedding insulation and indoor temperature have been observed in all regions, with $\mathrm{R}^{2}$ ranging between $0.688-0.939$. 
Table 4 The relationship between indoor air temperature and bedding insulation

374

\begin{tabular}{cccc}
\hline & Linear regression & $\mathrm{R}^{2}$ & $\mathrm{P}$ \\
\hline $\mathrm{SC}$ & $\mathrm{I}_{\mathrm{cl}}=-0.1708 \mathrm{~T}+6.64$ & 0.939 & 0.000 \\
$\mathrm{C}$ & $\mathrm{I}_{\mathrm{cl}}=-0.0972 \mathrm{~T}+4.82$ & 0.769 & 0.000 \\
$\mathrm{HSCW}$ & $\mathrm{I}_{\mathrm{cl}}=-0.0756 \mathrm{~T}+4.31$ & 0.874 & 0.000 \\
$\mathrm{M}$ & $\mathrm{I}_{\mathrm{cl}}=-0.0691 \mathrm{~T}+4.391$ & 0.688 & 0.001 \\
$\mathrm{HSWW}$ & $\mathrm{I}_{\mathrm{cl}}=-0.0925 \mathrm{~T}+4.735$ & 0.898 & 0.000 \\
China & $\mathrm{I}_{\mathrm{cl}}=-0.0856 \mathrm{~T}+4.605$ & 0.742 & 0.000 \\
\hline
\end{tabular}

\subsubsection{Air conditioning usage}

Air conditioners are commonly used in many areas of China to regulate the indoor thermal environment ${ }^{49-51}$, and they are also a major energy consumer in residential buildings in China

${ }^{52}$. Air conditioners can provide both cooling and heating, but they do not provide fresh air for rooms. In northern China, they are mainly used for cooling buildings in summer, as the heat demand in winter is fulfilled by central heating systems. In southern China, however, they are also used for cooling buildings in summer and heating buildings in winter. Figure $7 \mathrm{a}$ summarizes the availability of air conditioners in all households investigated, categorized by different climate regions. This clearly reflects that air conditioners are not very popular in the $\mathrm{M}$ region due to its mild outdoor climate throughout the year, as reflected in Figure 3a. The SC region had the same phenomenon due to the existence of central heating in winter and a cool outdoor climate in summer (referring to Figure 3a). For all other climatic regions, air conditioners are available in over $80 \%$ of the households investigated.

Figure $7 \mathrm{~b}$ compares the use of air conditioners when sleeping in different climatic regions and different seasons. From this comparison, it can be observed that in summer, the residents of the 
HSCW, the HSWW and the $\mathrm{C}$ regions actively used air conditioners when sleeping

392 (approximately half of the monitored cases). The residents of the SC region, however, rarely 393 used air conditioners, and this conclusion aligns with the low installation rate of air conditioners 394 in this region. Due to the mild outdoor climate during transitional season, the residents of all 395 regions did not seem to use air conditioners to maintain indoor thermal environment when 396 sleeping. In winter, only some residents in the HSCW regions were found to use air conditioners to heat their bedrooms. Additionally, no usage of air conditioners in winter was found from the $\mathrm{M}$ region, the $\mathrm{SC}$ region and the $\mathrm{C}$ region, as the first one has mild outdoor climate in winter, and the latter two have central heating systems to maintain warm indoor temperature. In addition to usage of air conditioners, this study also collected information about the setpoints 401 of the cooling and heating systems selected by the participants. In summer, the average temperature setpoints of air conditioners were found to be $26.9^{\circ} \mathrm{C}$ for the $\mathrm{C}$ region, $25.8^{\circ} \mathrm{C}$ for the $\mathrm{HSCW}$ region and $26.1^{\circ} \mathrm{C}$ for the HSWW regions, which were not significantly different

404 from each other. Additionally, all these values were close to the recommended cooling set point, 405 in the Chinese standard ${ }^{53}$. In winter, the average temperature set point of air conditioners in the HSCW region was found to be $22.5^{\circ} \mathrm{C}$, lower than the setpoint for summer. It is much possibly because of the higher bedding insulation levels adopted. 


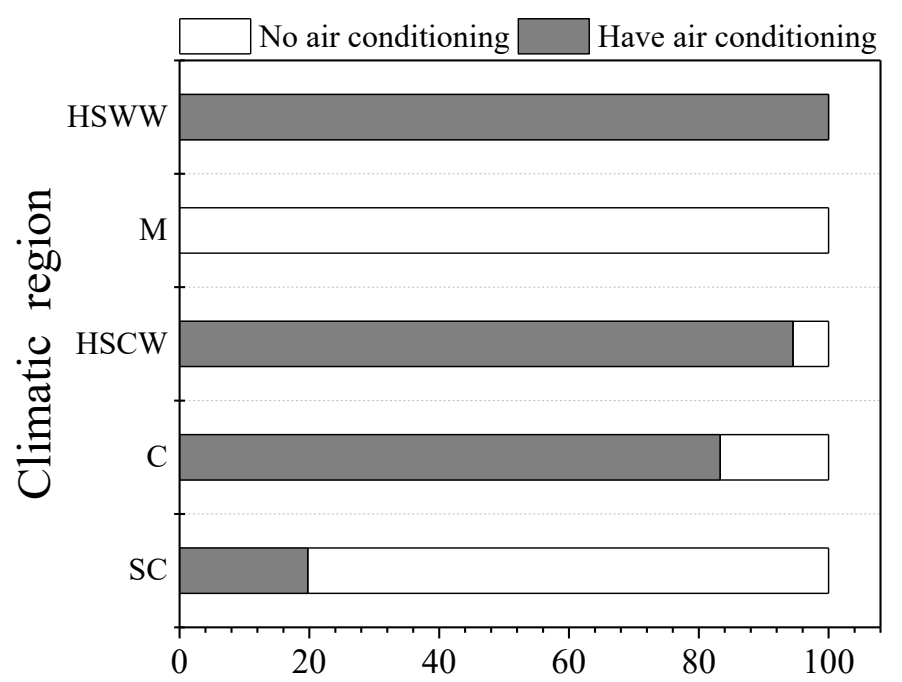

The proportion of air conditioning in the bedroom/ $\%$

(a) Proportion of installing air conditioners

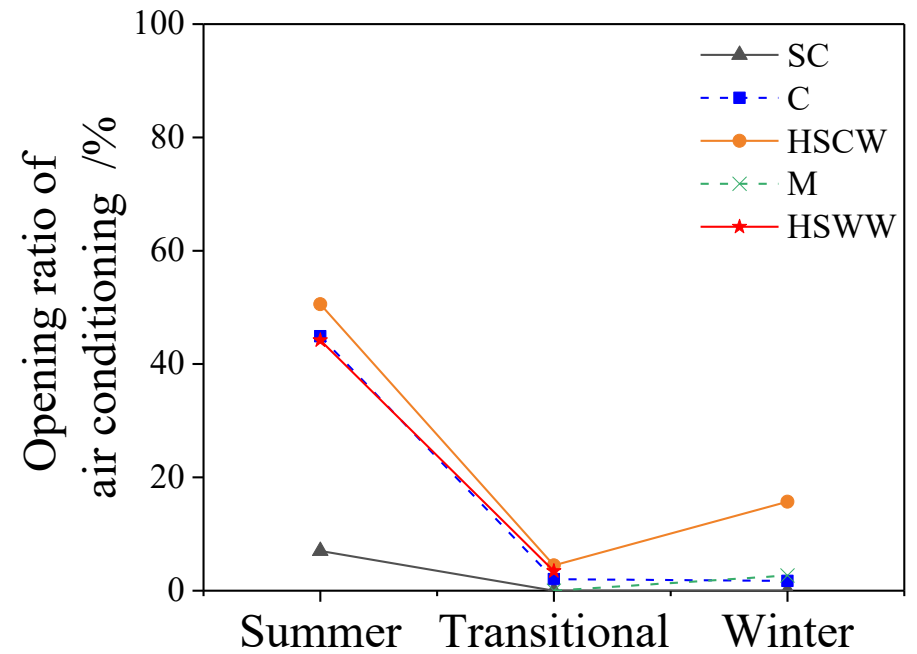

(b) Seasonal variations

Figure 7 Availability and usage of air conditioners when people are sleeping

\subsubsection{Window usage}

414 Windows are an effective way to regulate indoor thermal environment and air quality 415 especially during transitional and summer seasons ${ }^{54}$, since split-cooling AC units do not 
provide fresh air and can help to save building energy requirements ${ }^{55}$. Therefore, it is worthy investigating how occupants use this adaptive opportunity during their sleeping time. Figure 8 compares the percentage of open windows during sleeping period among different climatic regions and different seasons. Clearly, people in all climate regions preferred to keep their bedroom windows open in summer when sleeping, reflecting their preference of using natural

421 ventilation to regulate their indoor thermal environment ${ }^{56}$. For transitional season, the climatic regions in southern China, namely, the HSCW, the M and the HSWW regions, were found to have more open windows during sleeping time than those in northern China, and this may well be due to their higher outdoor temperature in this season, as shown in Figure 1a. The same phenomenon could be observed for winter season as well; About the impact from season, fewer open windows were found in winter than the other two seasons, and this may well because of the colder outdoor environment.

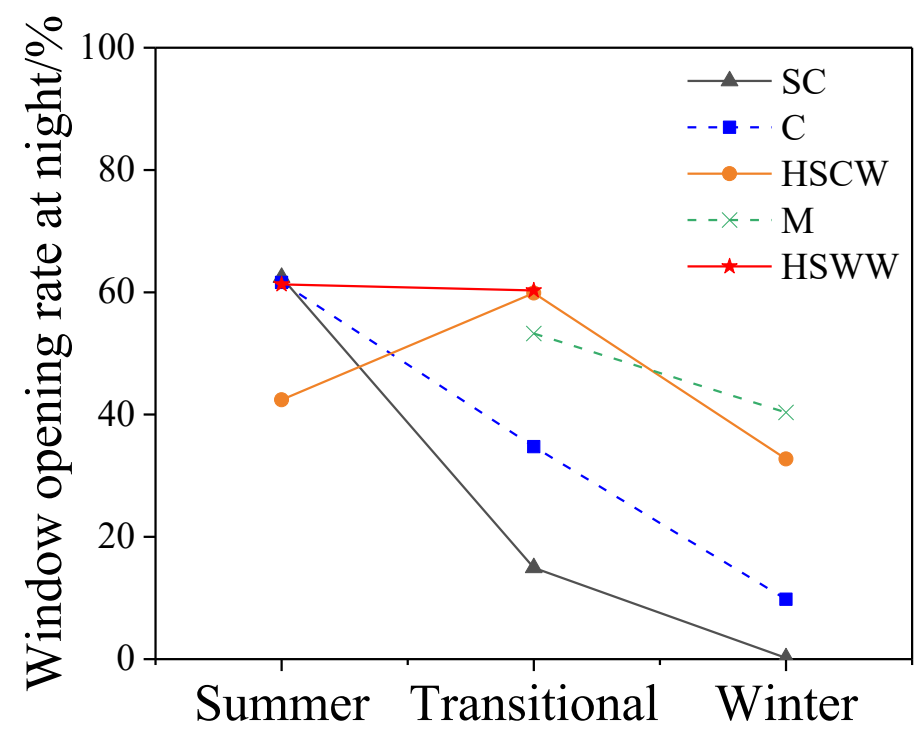




\subsubsection{Simultaneous usage of both $\mathrm{AC}$ and window}

433

434

435

436

437

Opening windows and using an air conditioning are both effective opportunities to regulate indoor thermal environment. When both are used simultaneously, however, it may lead to energy waste ${ }^{58}$. Table 5 has listed the calculated proportion of time when both adaptive opportunities were used at the same time in the nighttime in summer. According to the figures provided, people living in southern China, including the HSCW and the HSWW regions, were more intending to keep their windows open while using air conditioners when sleeping, than those living in northern China, including the $\mathrm{SC}$ and the $\mathrm{C}$ regions, agreeing with the findings from awake time ${ }^{60} 61$. This kind of behavioral combination, however, will definitely provide better control of indoor air quality and thermal comfortability, which will result in better performance in the next day ${ }^{62}$. Unfortunately, this aspect was not covered in this study. Additionally, the questionnaire designed for this study did not ask participants to indicate window opening areas, so whether the windows were slightly open or fully open could not be differentiated, and this will affect the amount of energy used to treat the outdoor air when windows are open with air conditioners on.

Table 5 Proportion of time using both air conditioners and windows simultaneously when sleeping

\begin{tabular}{ccccc}
\hline & SC & C & HSCW & HSWW \\
\hline $\begin{array}{c}\text { Proportion } \\
(\%)\end{array}$ & 0 & 9.8 & 11.8 & 18.5 \\
\hline
\end{tabular}




\section{Conclusions}

452 People spend almost one-third of their live sleeping, and good sleep quality is very important

453 for people's health and productivity during daytime. To promote sleep quality, thermal comfort

454 is very important, and quantitative evidence about the actual thermal environment when people

455 are sleeping and, their adaptive actions before sleeping becomes extremely important for

456 estimating building performance. Additionally, due to the vast territory and various climate

457 conditions in China, people may experience different thermal environment and may perform

458 different adaptive actions before sleeping to maintain good sleep quality. This paper, therefore,

459 has introduced some major results from a year-long field longitudinal study about the nighttime

460 thermal environment and people's adaptive actions, performed in five different climatic regions

461 in China. In the study, both objective measurements, including temperature and relative

462 humidity, and subjective measurements, including thermal sensation, bedding insulation,

463 window behavior and air conditioning usage, were collected, and followings are the main

464 findings from this study:

1. Cities in northern China have much colder and drier outdoor thermal environments when sleeping than those in southern China, especially during winter and transitional seasons. However, people have used available adaptive opportunities, such as heating systems and air-conditioning systems to regulate their indoor thermal environment. In summer and transitional seasons, the indoor sleep thermal environment in northern China was found to be similar to southern China. In winter season, the indoor sleep thermal environment in northern China was found to be even better than southern China. 
lower indoor temperature in winter than those living in northern China. This difference, however, seemed to be nonsignificant for transitional and summer seasons.

3. People from southern and northern China seemed to have similar thermal sensations in transitional season but different sensations in winter and summer seasons. However, most votes (approximately 70\%) were still between -1 and +1 , indicating good feeling in thermal comfort. For the remaining $30 \%$, there is still space for improvement of thermal environment in different regions and seasons.

4. Bedding insulation is a major adaptive opportunity allowing people to maintain thermal comfort when sleeping. The bedding insulation level was found to be highly correlated with indoor air temperature and season. Additionally, people living in northern China preferred lower bedding insulation levels in both summer and winter, comparing to those living in southern China.

5. Air conditioners are popularly used in summer for cooling for the cold region, the hot summer and cold winter region, and the hot summer and warm winter region., In winter, people living in the hot summer and cold winter region would use them for heating. The average AC setpoints were found to be approximately $26^{\circ} \mathrm{C}$ for cooling in all climatic regions. However, the measured temperature near participants' beds was mostly between $28-30^{\circ} \mathrm{C}$, which may due to the mixture of treated air and indoor warm air, or the location of AC thermostats.

6. Windows were used as a major adaptive strategy in both transitional and summer seasons in all climatic regions. In the winter, however, most windows in the cold and severely cold regions were found to be closed. In the cold region, the hot summer and cold winter region, 
and the hot summer and warm winter region, simultaneous usage of windows and air conditioners were observed occasionally leading to potential energy waste.

This study tried to provide quantitative evidence about the actual thermal environment during sleeping and the adaptive actions people performed before sleeping in different climatic regions in China. In the future, people's sleeping quality will be collected as well to support the evaluate of indoor thermal environment.

Additionally. CO2 concentration, as an important indicator of indoor air quality, will also be included in the environmental monitoring, to reflect the impact opening windows on indoor air quality, especially when both windows are open with air conditioners on.

\section{References}

1. Telzer EH, Fuligni AJ, Lieberman MD, Galvan A. The effects of poor quality sleep on brain function and risk taking in adolescence. Neurolmage. 2013;71:275-283.

2. Miller MA, Cappuccio F. Biomarkers of cardiovascular risk in sleep-deprived people. Journal of Human Hypertension. 2013;27:583-588.

3. Zeitlhofer J, Schmeiser-Rieder A, Tribl G, et al. Sleep and quality of life in the Austrian population. Acta Neurologica Scandinavica. 2010;102:249-257.

4. He M, Lian Z, Chen P. Evaluation on the performance of quilts based on young people's sleep quality and thermal comfort in winter. Energy and Buildings. 2019;183:174-183.

5. Miyata S, Noda A, Iwamoto K, Kawano N, Okuda M, Ozaki NJJoSR. Poor sleep quality impairs cognitive performance in older adults. Journal of Sleep Research 2013;22:535-541.

6. Xiong J, Ma T, Lian Z, Dear Rd. Perceptual and physiological responses of elderly subjects to moderate temperatures. Building and Environment. 2019;156:117-122.

7. Lan L, Tsuzuki K, Liu Y, Lian ZW. Thermal environment and sleep quality: A review. Energy and Buildings. 2017:S0378778817317681.

8. Lan L, Xia L, Tang J, Zhang X, Wang Z. Elevated air flow can maintain sleep quality and thermal comfort of the elderly in a hot environment. Indoor Air. 2019;29.

9. King AC, Oman RF, Brassington GS, Bliwise DL, Haskell WLJJ. Moderate-intensity exercise and selfrated quality of sleep in older adults. . Jama Journal of the American Medical Association. 1997;277:32-37.

10. Aschoff J, Biebach H, Heise A, Schmidt TJHLfA, Man. Day-Night variation in heat balance - Heat Loss from Animals and Man - 8. Heat Loss from Animals and Man. 1974;34(1):147-172.

11. Ranson RP, Organization WH. Guidelines for healthy housing. environmental health. 1988;31.

12. Levermore G, Muneer T, Sanders C, Page JJAP. CIBSE Guide A Environmental design. 2006. 
13. ISO. ISO 7730: 2005-Ergonomics of the thermal environment-Analytical determination and interpretation of thermal comfort using calculation of the PMV and PPD indices and local thermal comfort criteria. 2005.

14. ASHRAE. ASHRAE Standard 55-2013: Thermal environmental conditions for human occupancy. American Society of Heating, Refrigerating, and Air- Conditioning Engineers. 2013.

15. EN15251. CEN Standard : Indoor environmental input parameters for design and assessment of

19. Palca JW, Walker JM, Berger RJ. Thermoregulation, metabolism, and stages of sleep in coldacoustics. Thermal Environment, Lighting Acoustics, European Committee for Standardization, Brussels. 2007.

16. GB-50736. Design code for heating ventilation and air conditioning of civil buildings. Ministry of Housing Urban-Rural Development of the People's sepublic of China Beijing. 2012.

17. Lan L, Qian XL, Lian ZW, Lin YB. Local body cooling to improve sleep quality and thermal comfort in a hot environment. Indoor Air. 2018;28:135-145.

18. Haskell EH, Palca JW, Walker JM, Berger RJ, Electroencephalography HCHJ, Neurophysiology C. The effects of high and low ambient temperatures on human sleep stages. Electroencephalography and Clinical Neurophysiology. 1981;51:494-501.

exposed men. Journal of Applied Physiology. 1986;61:940-947.

20. Nisi JD, Ehrhart J, Galeou M, Physiology JPLJEJoA, Physiology O. Influence of repeated passive body heating on subsequent night sleep in humans. European Journal of Applied Physiology Occupational Physiology. 1989;59:138-145.

21. Lan L, Pan L, Lian Z, Huang H, Lin Y. Experimental study on thermal comfort of sleeping people at different air temperatures. Building and Environment. 2014;73:24-31.

22. Li P, Lian Z, Li L. Investigation of sleep quality under different temperatures based on subjective and physiological measurements. Hvac \&R Research. 2012;18:1030-1043.

23. Rohlesjr F, Munson DM. Sleep and the sleep environment temperature. Journal of Environmental Psychology. 1981;1:207-214.

24. Manzar MD, Sethi M, Hussain ME. Humidity and sleep: a review on thermal aspect. Biological rhythm research. 2012;43:439-457.

25. Pan L, Lian Z, Lan L. Investigation of gender differences in sleeping comfort at different environmental temperatures. Indoor and Built Environment. 2012;21:811-820.

26. Lan L, Pan L, Lian Z, Huang H, Lin Y. Experimental study on thermal comfort of sleeping people at different air temperatures. Building and Environment. 2014;73:24-31.

27. Lin Z, Deng S. A study on the thermal comfort in sleeping environments in the subtropicsdeveloping a thermal comfort model for sleeping environments. Building and Environment. 2008:43:70-81.

28. Lan L, Zhai ZJ, Lian Z. A two-part model for evaluation of thermal neutrality for sleeping people. Building and Environment. 2018;132:319-326.

29. Lin Z, Deng S. A questionnaire survey on sleeping thermal environment and bedroom air conditioning in high-rise residences in Hong Kong. Energy and Buildings. 2006;38(11):1302-1307.

30. Kim M, Chun C, Han J. A Study on Bedroom Environment and Sleep Quality in Korea. Indoor and Built Environment. 2010;19:123-128.

31. Imagawa H, Rijal HB. Field survey of the thermal comfort, quality of sleep and typical occupant behaviour in the bedrooms of Japanese houses during the hot and humid season. Architectural 
Science Review. 2015;58:11-23.

32. Liu Y, Li T, Song C, Wang D, Liu JJS, Environment TftB. Field study of different thermal requirements based on the indoor activities patterns of rural residents in winter in Northwest China. Science Technology for the Built Environment. 2018:1-11.

33. Wang Z ZT. Study on Thermal Comfort of Sleeping Farmhouse in Winter in severe cold regions. Journal of HV\& AC. 2019;9:97-102.

34. De Dear RJ, Brager GS. Thermal comfort in naturally ventilated buildings: revisions to ASHRAE Standard 55. Energy and Buildings. 2002;34:549-561.

35. GB-50176. Thermal design code for civil building. In: The Standardization Administration of China Beijing; 2016.

36. Lin Z, Deng S. A study on the thermal comfort in sleeping environments in the subtropicsMeasuring the total insulation values for the bedding systems commonly used in the subtropics. Building and Environment. 2008:43:905-916.

37. Qi Y, Liu J, Lai D, Zhang H, Yoshino H. Large-Scale and Long-Term Monitoring of the Thermal Environments and Adaptive Behaviors in Chinese Urban Residential Buildings. Building and Environment. 2020;168:106524.

38. Nguyen JL, Schwartz J, Dockery DW. The relationship between indoor and outdoor temperature,apparent temperature, relative humidity, and absolute humidity. Indoor Air. 2014;24:103-112.

39. M.Luo, B.Cao, Q.Ouyang, Y.Zhu. Indoor human thermal adaptation: dynamic processes and weighting factors. Indoor Air. 2017;27:273-281.

40. Kong D, Liu H, Wu Y, Li B, Wei S, Yuan M. Effects of indoor humidity on building occupants' thermal comfort and evidence in terms of climate adaptation. Building and Environment. 2019;155:298-307.

41. Yu J, Zhu Y. Experimental study on the effects of climatic characteristics on people's adaptability to thermal environment. Journal of Southeast University. 2010;26:279-282.

42. Zhang $\mathrm{Y}$, Chen $\mathrm{H}$, Wang J, Meng Q. Thermal comfort of people in the hot and humid area of Chinaimpacts of season, climate, and thermal history. Indoor Air. 2016;26:820-830.

43. Humphreys MA, Nicol JFJATB. Understanding the adaptive approach to thermal comfort. 1998;104(1):991-1004.

44. $W$ Y, Y L, Hien WN, Zhou J. Thermal comfort requirements in the summer season in subtropical urban space. Intelligent Buildings International. 2014;6:224-238.

45. Morgan C, de Dear R. Weather, clothing and thermal adaptation to indoor climate. Climate Research. 2003;24:267-284.

46. Yu J, Cao G, Cui W, Ouyang Q, Y.Zhu. People who live in a cold climate: thermal adaptation differences based on availability of heating. Indoor Air. 2013;23:303-310.

47. De Dear R, Brager GS. The adaptive model of thermal comfort and energy conservation in the built environment. International journal of biometeorology. 2001;45:100-108.

48. De Carli M, Olesen BW, Zarrella A, Zecchin RJB, Environment. People's clothing behaviour according to external weather and indoor environment. Building and Environment. 2007;42:39653973.

49. Jian Y, Li Y, Wei S, Zhang Y, Bai ZJJoAA, Engineering B. A case study on household electricity uses and their variations due to occupant behavior in Chinese apartments in Beijing. Journal of Asian Architecture Building Engineering. 2015;14:679-686. 
50. Cao B, Zhu Y, Ouyang Q, Zhou X, Huang LJE, Buildings. Field study of human thermal comfort and thermal adaptability during the summer and winter in Beijing. Energy and Buildings. 2011;43:10511056.

51. Zhang YJB, Environment. Design criteria of built thermal environment for Hot Summer \& Warm Winter zone of China. Building and Environment. 2015;88:97-105.

52. Li C, Zhou J, Cao Y, et al. Interaction between urban microclimate and electric air-conditioning energy consumption during high temperature season. Applied Energy. 2014;117:149-156.

53. http://www.gov.cn/gongbao/content/2007/content_678925.htm.

54. Offerman F, Robertson J, Springer D, Brennan S, Woo TJH, Sustainable Buildings A. Window usage, ventilation, and formaldehyde concentrations in new California homes: summer field sessions. Healthy Sustainable Buildings. 2007.

55. Wang L, Greenberg S. Window operation and impacts on building energy consumption. Energy and Buildings. 2015;92:313-321.

56. Lai $\mathrm{D}$, Yue Q, Liu J, et al. Ventilation behavior in residential buildings with mechanical ventilation systems across different climate zones in China. Building and Environment. 2018;143:679-690.

57. Liu Q, Zhang Y, Meng Q. The Investigation of People Using Air Movement Actively in Summer in Hot-Humid Area of China. Applied Mechanics Materials. 2011;121-126:602-606.

58. Pan S, Wang X, Wei S, et al. Energy Waste in Buildings Due to Occupant Behaviour. 2017;105:22332238.

59. Yoshino $\mathrm{H}$, Yoshino $\mathrm{Y}$, Zhang Q, et al. Indoor thermal environment and energy saving for urban residential buildings in China. Energy and Buildings. 2006;38:1308-1319.

60. Hou J, Sun Y, Chen Q, et al. Air change rates in urban Chinese bedrooms. Indoor Air. 2019;29:828839.

61. Lai D, Jia S, Qi Y, Liu JJB, Environment. Window-opening behavior in Chinese residential buildings across different climate zones. Building and Environment. 2018;142:234-243.

62. Strøm-Tejsen P, Zukowska D, Wargocki P, Wyon DP. The effects of bedroom air quality on sleep and next-day performance. Indoor Air. 2016;26(5):679-686. 